\title{
Initiation of Systemic Therapy During the Last 30 Days of Life in Patients With Metastatic Castration-resistant Prostate Cancer
}

\author{
CARSTEN NIEDER $^{1,2}$, ELLINOR HAUKLAND $^{2}$, BÅRD MANNSÅKER $^{2}$, \\ ADAM PAWINSKI $^{2}$, ROSALBA YOBUTA ${ }^{2}$ and JAN NORUM ${ }^{1,3}$ \\ ${ }^{1}$ Department of Clinical Medicine, Faculty of Health Sciences, \\ UiT - The Arctic University of Norway, Troms $\phi$, Norway; \\ ${ }^{2}$ Department of Oncology and Palliative Medicine, Nordland Hospital, Bod $\phi$, Norway; \\ ${ }^{3}$ Department of Surgery, Finnmark Hospital, Hammerfest, Norway
}

\begin{abstract}
Background/Aim: Compared to intravenous taxane chemotherapy, newer orally-available and/or less toxic agents for metastatic castration-resistant prostate cancer (MCRPC) may be associated with higher likelihood of starting treatment in patients with adverse prognostic features and limited life expectancy. To test this hypothesis, we analyzed the rates of treatment initiation during the last 30 days of life in a realworld cohort of men with MCRPC. Patients and Methods: This was a retrospective analysis of 146 patients. Results: Seven patients $(5 \%)$ who started any systemic treatment during the last 30 days of life were identified. The likelihood of treatment initiation in the last 30 days of life correlated significantly with the number of lines of systemic treatment (higher risk for previously treated patients) and non-use of bone-targeted agents. Conclusion: Initiation of systemic therapy in the last 30 days of life was uncommon. This endpoint might complement other quality-of-care indicators.
\end{abstract}

Over the last decade, systemic treatment for metastatic castration-resistant prostate cancer (MCRPC) has improved $(1,2)$. New options such as abiraterone acetate, enzalutamide and Ra-223 have been approved (3-10). In contrast to docetaxel and cabazitaxel (11-13), two of these new therapies do not require intravenous administration. All three were shown to cause fewer side-effects than taxanes $(3,5,8$, 14). Reluctance to prescribe taxanes may be greater in patients with a poor performance status, older age and

Correspondence to: Dr. Carsten Nieder, Department of Oncology and Palliative Medicine, Nordland Hospital, 8092 Bodø, Norway. Tel: +47 75578449, Fax: +47 75534975, e-mail: carsten.nieder@nlsh.no

Key Words: Palliative chemotherapy, systemic therapy, docetaxel, prostate cancer, prognostic factors, quality-of-care. certain comorbidities. Due to their side-effect profile and, in part, oral route of administration, clinicians may be less restrictive in prescribing abiraterone acetate, enzalutamide or Ra-223 in patients with adverse prognostic features, many of whom are expected to have very limited life expectancy. Therefore, we hypothesized that the availability of these newer drugs may increase the likelihood of initiating a new line of treatment close to the end of life, i.e. the last 30 days of life. Numerous studies have shown that rates of administration of chemotherapy during the last 30 days of life (a quality-of-care indicator) remain too high (15-18). Overutilization of radiotherapy also contributes to suboptimal use of health care resources (19-22). Due to difficulties in estimating the remaining lifespan, termination of systemic treatment in due time may sometimes be challenging. In contrast, initiation of a new treatment is often more complex and thus potentially easier to prevent than continuation of an already ongoing treatment. Therefore, the rate of initiation of a new treatment in the last 30 days of life was evaluated in a patient population treated in a welldefined geographical region with a publicly-funded healthcare system that provides equal access to treatment irrespective of income, place of living and other potential socioeconomic barriers.

\section{Patients and Methods}

Patients and treatment. A retrospective single-institution study that included all consecutive patients with MCRPC who received systemic treatment at Nordland Hospital in Bodø, Norway was performed. The primary endpoint was initiation of a new treatment in the last 30 days of life, and therefore only patients who had died before data extraction in June 2017 were included. Overall, the study population consisted of 146 men. They were identified from the electronic patient record (EPR) systems of the hospital and had received at least one dose of systemic therapy (abiraterone acetate, 
enzalutamide, taxotere, cabazitaxel, Ra-223, denosumab or zoledronic acid). Formal assessment of a patient's prognosis, e.g., by nomogram or score was not required when starting new treatments.

Statistical methods. All analyses were performed with SPSS 23 (IBM, New York, NY, USA). Actuarial survival from imaging diagnosis of distant metastases was calculated with the KaplanMeier method. Date of death was known in all patients. Associations between different variables of interest were assessed with the chi-square or Fisher exact probability test (two-tailed). A $p$-value $\leq 0.05$ was considered statistically significant. As a retrospective quality of care analysis, no approval from the Regional Committee for Medical and Health Research Ethics (REK) was necessary. Similarly, no approval from the Norwegian Social Science Database (NSD) had to be obtained.

\section{Results}

Patient characteristics. The median age (range) at diagnosis of prostate cancer, distant metastases, and death was 68 years (range $=51-89$ years), 72.5 (range $=56-89$ years), and 76 (range $=57-96$ years), respectively. Forty-nine patients $(34 \%)$ had distant metastases at the time of diagnosis of prostate cancer. The majority $(n=97,66 \%)$ had metachronous metastatic disease after a median of 67 months from initial cancer diagnosis (range=3-244). In the latter group, 62 patients had developed MCRPC when they were diagnosed with distant metastases. When diagnosed with metastatic disease, 107 patients $(73 \%)$ had bone-only involvement and 35 (24\%) bone and lymph node metastases, most commonly in the abdomen and/or thorax. Only 4 patients (3\%) had visceral distant metastases. Further information is shown in Table I.

Systemic treatment. During the time period of this study our institution followed the pathways outlined in the national Norwegian guidelines for management of prostate cancer. The public health care system is based on strong adherence to these guidelines, providing equal access to high-quality care irrespective of place of living (9). Regular updates ensured that new drugs became available after their approval by the European Medical Agency. None of our patients participated in a clinical trial or early access program. All of them received standard treatment, which however evolved every time new therapies were introduced. Early during the study period, treatment consisted of endocrine therapy including total androgen blockade followed by anti-androgen withdrawal, and after development of MCRPC prednisolone and taxotere, maybe followed by mitoxantrone. Stepwise, further options (cabazitaxel, abiraterone acetate, and enzalutamide) became available. All patients continued on luteinizing hormonereleasing hormone (LHRH) agonists, unless bilateral orchiectomy had been performed. Individualized decisions were made regarding the sequence of treatments. Forty-seven patients $(32 \%)$ were treated during the time period when abiraterone acetate was approved by the Norwegian regional
Table I. Patient characteristics at the time of diagnosis with prostate cancer $(n=146)$.

\begin{tabular}{|c|c|c|}
\hline Parameter & $\mathrm{n}$ & $\%$ \\
\hline Married/partner & 111 & 76 \\
\hline Single & 29 & 20 \\
\hline Unknown & 6 & 4 \\
\hline Place of living: Bod $\emptyset^{\mathrm{a}}$ & 66 & 45 \\
\hline Place of living: surrounding communities & 80 & 55 \\
\hline Charlson comorbidity index 0 & 75 & 51 \\
\hline Charlson comorbidity index 1 & 44 & 30 \\
\hline Charlson comorbidity index $>1$ & 17 & 12 \\
\hline Unknown & 10 & 7 \\
\hline Gleason score $\geq 8$ & 82 & 56 \\
\hline Gleason score $<8$ & 64 & 44 \\
\hline NCCN risk category at first cancer diagnosis: M1 & 49 & 34 \\
\hline NCCN risk category at first cancer diagnosis: N1 & 12 & 8 \\
\hline $\mathrm{NCCN}$ risk category at first cancer diagnosis: high/very high & 56 & 38 \\
\hline NCCN risk category at first cancer diagnosis: intermediate & 29 & 20 \\
\hline Initial surgical treatment & 15 & 10 \\
\hline Initial radiotherapy \pm endocrine treatment & 14 & 10 \\
\hline Initial LHRH agonist & 72 & 49 \\
\hline Initial antiandrogen & 14 & 10 \\
\hline Initial orchiectomy & 5 & 3 \\
\hline Initial watchful waiting & 26 & 18 \\
\hline Less than 5 bone metastases (isotope bone scan) ${ }^{b}$ & 43 & 30 \\
\hline At least 5 bone metastases ${ }^{b}$ & 91 & 62 \\
\hline Unknown ${ }^{b}$ & 12 & 8 \\
\hline
\end{tabular}

aApproximately 50,000 inhabitants; surrounding communities: approximately 80,000 inhabitants; bAt the time of diagnosis of metastatic disease. NCCN: National Comprehensive Cancer Network; LHRH: luteinizing hormone-releasing hormone.

Table II. Systemic therapy after diagnosis of distant metastases $(n=146)$.

\begin{tabular}{lrr}
\hline Parameter & $\mathrm{n}$ & $\%$ \\
\hline Overall systemic therapy: bone-targeting only & 46 & 32 \\
Overall systemic therapy: chemo only $^{\mathrm{a}}$ & 25 & 17 \\
Overall systemic therapy: both $^{\text {O }}$ & 75 & 51 \\
One line only $^{\mathrm{a}}$ & 93 & 64 \\
Two or more lines $^{\mathrm{a}}$ & 53 & 36 \\
Received any taxotere & 86 & 59 \\
Received any mitoxantrone & 8 & 6 \\
Received any cabazitaxel & 6 & 4 \\
Received abiraterone acetate after chemotherapy & 37 & 25 \\
Received abiraterone acetate before chemotherapy & 12 & 8 \\
Received enzalutamide after chemotherapy & 17 & 12 \\
Received Ra-223 & 10 & 7 \\
\hline
\end{tabular}

ancludes cytotoxic chemotherapy, abiraterone acetate, enzalutamide, Ra-223.

health authorities, the first modern non-taxane treatment option. The other patients were treated in the earlier docetaxel era. Overall, 10 patients $(7 \%)$ received Ra-223 and $5(3 \%)$ strontium-based radionuclide therapy. External bone 
Table III. Patients who started systemic treatment in the last 30 days of life ( $n=7$, including two patients who died from toxicity within 30 days of chemotherapy administration).

\begin{tabular}{lccccc}
\hline Patient nr. & Index treatment & Previous treatment & Age, years & ECOG PS & PSA doubling time, months \\
\hline 1 & Abiraterone acetate & Enzalutamide & 75 & 3 & $<2$ \\
2 & Abiraterone acetate & Taxotere & 60 & 1 & $<2$ \\
3 & Zoledronic acid & None & 72 & 3 & $<2$ \\
4 & Enzalutamide & A followed by T* & 76 & 1 & 2.5 \\
5 & Enzalutamide & None & 80 & 2 & $<2$ \\
6 & Cabazitaxel & T-A-E** & 73 & 1 & 4 \\
7 & Taxotere & None & 74 & 2 & $<2$ \\
\hline
\end{tabular}

ECOG PS: Eastern Cooperative Oncology Group performance status; PSA; prostate-specific antigen. *Abiraterone acetate followed by taxotere; **Taxotere followed by abiraterone acetate and then enzalutamide.

Table IV. Associations between initiation of systemic treatment in the last 30 days of life (IST30) and different patient- or treatment-related parameters.

\begin{tabular}{lcccc}
\hline Primary endpoint & Parameter & Patient numbers & $p$-Value (Fisher exact probability test) & Likelihood of IST30 \\
\hline IST30 & RT30 yes/no & 3,4 & 0.02 & \\
No IST30 & RT30 yes/no & 10,129 & 0.02 & No bisphosphonate or denosumab: 16\% \\
IST30 & BT yes/no & 3,4 & & Bisphosphonate or denosumab: $2 \%$ \\
No IST30 & BT yes/no & 21,118 & 0.02 & Group 2: $16 \%$ \\
IST30 & Overall Tx 1/2/3 & $1,4,2$ & & Group 1: $2 \%$, group 3: $3 \%$ \\
No IST30 & Overall Tx 1/2/3 & $45,21,73$ & $1,2,2,2$ & Group 3: $8 \%$ group 2: $7 \%$ \\
IST30 & Lines B/1/2/3 & $43,47,27,22$ & Group B: $2 \%$, group $1: 4 \%$ \\
No IST30 & Lines B $/ 1 / 2 / 3$ & & \\
\hline
\end{tabular}

RT30: Received radiotherapy in the last 30 days of life; BT: received any bisphosphonate or denosumab, overall Tx (treatment) 1: bone-targeted only; 2: chemotherapy/abiraterone acetate/enzalutamide without bone-targeted agents; 3 : chemotherapy/abiraterone acetate/enzalutamide with bonetargeted agents; Lines B: bone-targeted only; 1: 1 line of chemotherapy/abiraterone acetate/enzalutamide/Ra-223; 2: 2 lines, $3: 3$ or more lines. All other parameters including age, comorbidity, synchronous $v s$. metachronous metastases, and place of living were not significant.

irradiation was common $(\mathrm{n}=120,82 \%)$. Further information is shown in Table II.

Survival and primary endpoint. Median overall survival with metastatic disease was 26.6 months (68.5 months from first cancer diagnosis). When calculated from diagnosis of distant metastases, survival was less than 6 months in 9 patients (6\%) and 6-12 months in 15 patients (10\%).

Overall, 7 patients $(5 \%)$ started a new treatment during the last 30 days of life. The rates were not significantly different in the two time periods, i.e. the taxane-only era and the abiraterone acetate/enzalutamide/Ra-223 era (6 vs. $4 \%$, $p=0.68)$. Two of the 7 patients, both older than 70 years, died from chemotherapy toxicity. The treatment sequence was taxotere, abiraterone acetate, enzalutamide and cabazitaxel in one of these patients. The other patient had received taxotere as first-line approach. Information about all 7 patients is shown in Table III. In 5 of them, death was considered unrelated to toxicity, meaning that the estimation of the patients' prognosis was overly optimistic.
Overall, $9 \%$ of the patients were irradiated within the last 30 days of life (radionuclide in 1 case, external beam in 12 cases). The most common scenario was external beam radiotherapy for bone pain $(n=9)$. The rate of radiotherapy in the last 30 days of life correlated with the rate of initiation of systemic treatment in the same time period $(p=0.02)$. Out of 7 patients with systemic treatment initiation, $3(43 \%)$ also had radiotherapy. Out of 139 patients without initiation of systemic therapy in the last 30 days, only $7 \%(n=10)$ had radiotherapy. Table IV shows other statistically significant correlations between treatment initiation and patient- or treatment-related factors.

\section{Discussion}

During the last 15 years, several new systemic treatment options for patients with MCRPC have become available. The first one was docetaxel (11). Approximately the same magnitude of survival improvement was seen with cabazitaxel (12), abiraterone acetate (3), enzalutamide (5), and Ra-223 (8). None of these treatments is able to prevent death from MCRPC (23- 
25). In a previous study of aggressive end-of-life care that included approximately 1,500 patients with metastatic prostate cancer younger than age 65 years, slightly more than $10 \%$ received chemotherapy within the last 14 days of life (17). This quality-of-care indicator, together with other endpoints, has repeatedly been reported in a broad range of oncology studies (26-28). Reducing overly aggressive end-of-life care is warranted from a patient, caregiver/family and payer/health-care administrator perspective. In the present study, we focused on a different endpoint that may be assessed in a comprehensive quality-of-care analysis, namely initiation of systemic treatment in the last 30 days of life. We became interested in this endpoint because we were worried about the possibility that orally available and/or rather well-tolerated agents, such as abiraterone acetate, enzalutamide and Ra-223, would reduce physicians' reluctance to initiate treatment in poor-prognosis patients, compared to taxane-based chemotherapy. Traditionally, a critical assessment of age, frailty, comorbidity, performance status and organ function has resulted in restricted chemotherapy use in patients with unfavorable risk-benefit-ratio in our clinical practice. The choice of endpoint was also influenced by the uncertainty of retrospective assessment of oral medications in ambulatory patients with terminal prostate cancer, which may result in under-reporting.

It was reassuring to see that only $5 \%$ of the patients started a new systemic treatment during the last 30 days of life, even when applying a broad definition of systemic treatment, which included bone-targeted agents. The drugs that were hypothesized to lower the barrier for treatment initiation were not overrepresented. However, due to the small number of events, our study had limited statistical power and this fact may also have hampered our ability to identify patient-related risk factors such as performance status (PS). A strict policy of limiting treatment initiation to patients with PS 0-2 would have reduced our rate from 5 to $3 \%$. The fact that the primary endpoint also was associated with palliative radiotherapy in the last 30 days of life and that very short PSA-doubling time was common, suggests that symptom burden might have influenced the decision to start systemic therapy. Even in appropriately selected patients, active systemic therapy might cause serious and sometimes fatal toxicities. Also, in our study, two patients died from taxane-related side-effects. The risk of starting treatment in the last 30 days of life was lowest in patients who started with bone-targeted agents (2\%), followed by first-line chemotherapy/abiraterone acetate/enzalutamide/Ra$223(4 \%)$. For second- and third-line treatment with one of these agents, risk increased to $7-8 \%$. This finding probably reflects the disease biology and timeline of progression.

Patients managed without bone-targeted agents were at higher risk $(16 \%)$ of starting a new treatment, compared to those who received such agents, either alone or in combination with other drugs. Possibly, there was a large burden of visceral metastases in cases where bone-targeted agents were omitted, which would result in shorter survival (29). However, our database did not contain information about patterns of spread for each time-point of treatment initiation.

Bergman et al. reported that chemotherapy was never initiated within 3 months of death, however in a small study of 60 men, all of whom uninsured, with low income and enrolled in a public assistance program (30). Besides patient selection, this study was performed in the docetaxel-only era. In a prospective randomized trial of docetaxel/estramustine $v s$. mitoxantrone less than $3 \%$ of the patients died within 30 days of enrollment (31). In a different study, less than $3 \%$ of the patients died from cabazitaxel-related toxicity (32). In a study that was not limited to men with prostate cancer, $4 \%$ of the patients died within 30 days of the first cycle of a new course of chemotherapy (33). The study included 1,131 patients, but did not collect data on endocrine treatment. Compared to these heterogeneous studies, our rate of $5 \%$ (including even bonetargeted agents) is not alarmingly high. We recommend largescale studies with higher statistical power to firmly reject the hypothesis that treatment initiation in the last 30 days of life is more common for orally available and/or less toxic agents such as abiraterone acetate, enzalutamide and Ra-223.

\section{Conclusion}

Initiation of systemic therapy in the last 30 days of life was uncommon and not clearly related to any particular class of agents. In contrast, its likelihood was higher in patients who had received systemic treatment before. This endpoint might complement other quality-of-care indicators, such as rate of administration of systemic therapy in the last 2 weeks of life.

\section{Conflicts of Interest}

The Authors declare that they have no competing interests regarding this study.

\section{References}

1 Crawford ED, Higano CS, Shore ND, Hussain M and Petrylak DP: Treating patients with metastatic castration resistant prostate cancer: A comprehensive review of available therapies. J Urol 194: 1537-1547, 2015.

2 Graham L and Schweizer MT: Targeting persistent androgen receptor signaling in castration-resistant prostate cancer. Med Oncol 33: 44, 2016.

3 de Bono JS, Logothetis CJ, Molina A, Fizazi K, North S, Chu L, Chi KN, Jones RJ, Goodman OB Jr, Saad F, Staffurth JN, Mainwaring P, Harland S, Flaig TW, Hutson TE, Cheng T, Patterson H, Hainsworth JD, Ryan CJ, Sternberg CN, Ellard SL, Fléchon A, Saleh M, Scholz M, Efstathiou E, Zivi A, Bianchini D, Loriot Y, Chieffo N, Kheoh T, Haqq CM and Scher HI: Abiraterone and increased survival in metastatic prostate cancer. N Engl J Med 364: 1995-2005, 2011. 
4 Ryan CJ, Smith MR, Fizazi K, Saad F, Mulders PF, Sternberg CN Miller K, Logothetis CJ, Shore ND, Small EJ, Carles J, Flaig TW, Taplin ME, Higano CS, de Souza P, de Bono JS, Griffin TW, De Porre P, Yu MK, Park YC, Li J, Kheoh T, Naini V, Molina A and Rathkopf DE: Abiraterone acetate plus prednisone versus placebo plus prednisone in chemotherapy-naive men with metastatic castration-resistant prostate cancer (COU-AA-302): final overall survival analysis of a randomised, double-blind, placebocontrolled phase 3 study. Lancet Oncol 16: 152-160, 2015.

5 Scher HI, Fizazi K, Saad F, Taplin ME, Sternberg CN, Miller K, de Wit R, Mulders P, Chi KN, Shore ND, Armstrong AJ, Flaig TW, Fléchon A, Mainwaring P, Fleming M, Hainsworth JD, Hirmand M, Selby B, Seely L and de Bono JS: Increased survival with enzalutamide in prostate cancer after chemotherapy. N Engl J Med 367: 1187-1197, 2012.

6 Loriot Y, Miller K, Sternberg CN, Fizazi K, De Bono JS, Chowdhury S, Higano CS, Noonberg S, Holmstrom S, Mansbach H, Perabo FG, Phung D, Ivanescu C, Skaltsa K, Beer TM and Tombal B: Effect of enzalutamide on health-related quality of life, pain, and skeletal-related events in asymptomatic and minimally symptomatic, chemotherapy-naive patients with metastatic castration-resistant prostate cancer (PREVAIL): results from a randomised, phase 3 trial. Lancet Oncol 16: 509-521, 2015.

7 Oh WK, Miao R, Vekeman F, Sung J, Cheng WY, GauthierLoiselle M, Dhawan R and Duh MS: Patient characteristics and overall survival in patients with post-docetaxel metastatic castration-resistant prostate cancer in the community setting. Med Oncol 34: 160, 2017.

8 Parker C, Nilsson S, Heinrich D, Helle SI, O’Sullivan JM, Fosså SD, Chodacki A, Wiechno P, Logue J, Seke M, Widmark A, Johannessen DC, Hoskin P, Bottomley D, James ND, Solberg A, Syndikus I, Kliment J, Wedel S, Boehmer S, Dall'Oglio M, Franzén L, Coleman R, Vogelzang NJ, O'Bryan-Tear CG, Staudacher K, Garcia-Vargas J, Shan M, Bruland ØS and Sartor $\mathrm{O}$ : Alpha emitter radium-223 and survival in metastatic prostate cancer. N Engl J Med 369: 213-223, 2013.

9 Norum J, Traasdahl ER, Totth A, Nieder C and Olsen JA: Health economics and radium-223 (Xofigo ${ }^{\circledR}$ ) in the treatment of metastatic castration resistant prostate cancer (mCRPC). A case history and a systematic review of the literature. Glob J Health Sci 8: 1-9, 2015.

10 Norum J and Nieder C: Treatments for metastatic prostate cancer (mPC): A review of costing evidence. Pharmacoeconomics 35: 1223-1236, 2017.

11 Tannock IF, de Wit R, Berry WR, Horti J, Pluzanska A, Chi KN, Oudard S, Théodore C, James ND, Turesson I, Rosenthal MA and Eisenberger MA: Docetaxel plus prednisone or mitoxantrone plus prednisone for advanced prostate cancer. N Engl J Med 351: 1502-1512, 2004.

12 de Bono JS, Oudard S, Ozguroglu M, Hansen S, Machiels JP, Kocak I, Gravis G, Bodrogi I, Mackenzie MJ, Shen L, Roessner M, Gupta S and Sartor AO: Prednisone plus cabazitaxel or mitoxantrone for metastatic castration-resistant prostate cancer progressing after docetaxel treatment: a randomised open-label trial. Lancet 376: 1147-1154, 2010.

13 Bando Y, Hinata N, Terakawa T, Furukawa J, Harada KI, Nakano Y and Fujisawa M: Activity of cabazitaxel in patients with metastatic castration-resistant prostate cancer after treatment with single or dual regimens of novel androgen receptor-targeting agents. Med Oncol 34: 163, 2017.
14 Ghatalia P, Pond GR, Templeton AJ and Sonpavde G: Effect of single-agent daily prednisone on outcomes and toxicities in metastatic castration-resistant prostate cancer: Pooled analysis of prospective studies. Clin Genitourin Cancer 16: e277-e287, 2018.

15 De Schreye R, Smets T, Annemans L, Deliens L, Gielen B, De Gendt $\mathrm{C}$ and Cohen $\mathrm{J}$ : Applying quality indicators for administrative databases to evaluate end-of-life care for cancer patients in Belgium. Health Aff (Millwood) 36: 1234-1243, 2017.

16 Dasch B, Kalies H, Feddersen B, Ruderer C, Hiddemann W and Bausewein C: Care of cancer patients at the end of life in a German university hospital: A retrospective observational study from 2014. PLoS One 12: e0175124, 2017.

17 Falchook AD, Dusetzina SB, Tian F, Basak R, Selvam N and Chen RC: Aggressive end-of-life care for metastatic cancer patients younger than age 65 years. J Natl Cancer Inst 109, 2017. doi: $10.1093 /$ jnci/djx028

18 Abdollah F, Sammon JD, Majumder K, Reznor G, Gandaglia G, Sood A, Hevelone N, Kibel AS, Nguyen PL, Choueiri TK, Selvaggi KJ, Menon M and Trinh QD: Racial disparities in endof-life care among patients with prostate cancer: A populationbased study. J Natl Compr Canc Netw 13: 1131-1138, 2015.

19 Murphy JD, Nelson LM, Chang DT, Mell LK and Le QT: Patterns of care in palliative radiotherapy: a population-based study. J Oncol Pract 9: e220-e227, 2013.

20 Guadagnolo BA, Liao KP, Elting L, Giordano S, Buchholz TA and Shih YC: Use of radiation therapy in the last 30 days of life among a large population-based cohort of elderly patients in the United States. J Clin Oncol 31: 80-87, 2013.

21 Nieder C, Angelo K, Dalhaug A, Pawinski A, Haukland E and Norum J: Palliative radiotherapy during the last month of life: Predictability for referring physicians and radiation oncologists. Oncol Lett 10: 3043-3049, 2015.

22 Angelo K, Norum J, Dalhaug A, Pawinski A, Aandahl G, Haukland E, Engljähringer K and Nieder C: Development and validation of a model predicting short survival (death within 30 days) after palliative radiotherapy. Anticancer Res 34: 877-885, 2014.

23 Heinrich D, Bektic J, Bergman AM, Caffo O, Cathomas R, Chi KN, Daugaard G, Keizman D, Kindblom J, Kramer G, Olmos D, Omlin A, Sridhar SS, Tucci M, van Oort I and Nilsson S: The contemporary use of radium-223 in metastatic castrationresistant prostate cancer. Clin Genitourin Cancer, 2017. doi: 10.1016/j.clgc.2017.08.020. [Epub ahead of print]

24 Oh WK, Miao R, Vekeman F, Sung J, Cheng WY, GauthierLoiselle M, Dhawan R and Duh MS: Real-world characteristics and outcomes of patients with metastatic castration-resistant prostate cancer receiving chemotherapy versus androgen receptor-targeted therapy after failure of first-line androgen receptor-targeted therapy in the community setting. Clin Genitourin Cancer, 2017. doi: 10.1016/j.clgc.2017.06.004 [Epub ahead of print]

25 Papazoglou D, Wannesson L, Berthold D, Cathomas R, Gillessen S, Rothermundt C, Hasler L, Winterhalder R, Barth A, Mingrone W, Nussbaum CU, von Rohr L, von Burg P, Schmid M, Richner J, Baumann S, Kühne R, Stenner F and Rothschild SI: Enzalutamide in patients with castration-resistant prostate cancer progressing after docetaxel: Retrospective analysis of the Swiss Enzalutamide named patient program. Clin Genitourin Cancer 15: e315-e323, 2017. 
26 Odejide OO, Cronin AM, Condron NB, Fletcher SA, Earle CC, Tulsky JA and Abel GA: Barriers to quality end-of-life care for patients with blood cancers. J Clin Oncol 34: 3126-3132, 2016.

27 Zakhour M, LaBrant L, Rimel BJ, Walsh CS, Li AJ, Karlan BY and Cass I: Too much, too late: Aggressive measures and the timing of end of life care discussions in women with gynecologic malignancies. Gynecol Oncol 138: 383-387, 2015.

28 Rautakorpi LK, Seyednasrollah F, Mäkelä JM, Hirvonen OM, Laitinen T, Elo LL and Jyrkkiö SM: End-of-life chemotherapy use at a Finnish university hospital: a retrospective cohort study. Acta Oncol 56: 1272-1276, 2017.

29 Halabi S, Kelly WK, Ma H, Zhou H, Solomon NC, Fizazi K, Tangen CM, Rosenthal M, Petrylak DP, Hussain M, Vogelzang NJ, Thompson IM, Chi KN, de Bono J, Armstrong AJ, Eisenberger MA, Fandi A, Li S, Araujo JC, Logothetis CJ, Quinn DI, Morris MJ, Higano CS, Tannock IF and Small EJ: Meta-analysis evaluating the impact of site of metastasis on overall survival in men with castration-resistant prostate cancer. J Clin Oncol 34: 1652-1659, 2016.

30 Bergman J, Chi AC and Litwin MS: Quality of end-of-life care in low-income, uninsured men dying of prostate cancer. Cancer 116: 2126-2131, 2010.
31 Petrylak DP, Tangen CM, Hussain MH, Lara PN Jr., Jones JA, Taplin ME, Burch PA, Berry D, Moinpour C, Kohli M, Benson MC, Small EJ, Raghavan D and Crawford ED: Docetaxel and estramustine compared with mitoxantrone and prednisone for advanced refractory prostate cancer. N Engl J Med 351: 15131520, 2004.

32 Heidenreich A, Scholz HJ, Rogenhofer S, Arsov C, Retz M, Müller SC, Albers P, Gschwend J, Wirth M, Steiner U, Miller K, Heinrich E, Trojan L, Volkmer B, Honecker F, Bokemeyer C, Keck B, Otremba B, Ecstein-Fraisse E and Pfister D: Cabazitaxel plus prednisone for metastatic castration-resistant prostate cancer progressing after docetaxel: results from the German compassionate-use programme. Eur Urol 63: 977-982, 2013.

33 Zdenkowski N, Cavenagh J, Ku YC, Bisquera A and Bonaventura A: Administration of chemotherapy with palliative intent in the last 30 days of life: the balance between palliation and chemotherapy. Intern Med J 43: 1191-1198, 2013.

Received November 23, 2018

Revised December 3, 2018

Accepted December 4, 2018 